Proc. Estonian Acad. Sci. Eng., 2006, 12, 1, 26-39

\title{
Dynamic coefficients in impact mechanics
}

\author{
Irina Hussainova ${ }^{\mathrm{a}}$, Klaus-Peter Schade ${ }^{\mathrm{b}}$ and Sergei Tisler $^{\mathrm{c}}$ \\ a Department of Materials Engineering, Tallinn University of Technology, Ehitajate tee 5, 19086 \\ Tallinn, Estonia; irhus@staff.ttu.ee \\ b SIVUS GmbH, Institute of Process, Environmental and Sensor Technology at the Chemnitz \\ University of Technology, Schulstrasse 38, 09125 Chemnitz, Germany \\ c Laboratory of Multiphase Media Physics, Tallinn University of Technology, Akadeemia tee 23A, \\ 12618 Tallinn, Estonia
}

Received 8 February 2005, in revised form 15 November 2005

\begin{abstract}
Since the erosion rate depends on energy exchange between particles and the material, a reformulation of the equations of the collision of two solid bodies is presented. The solution is adapted to the calculation of the energy, absorbed by the plain material surface during the impact of a spherical particle. It has been observed that energy loss strongly depends on dynamic coefficients, on the coefficient of velocity restitution after impact, $k$, and coefficient of dynamic friction, $f$. The new method and experimental equipment for the determination of the coefficients are described.
\end{abstract}

Key words: particle-wall collision, coefficient of restitution, coefficient of dynamic friction, energy dissipation.

\section{INTRODUCTION}

The definition of erosion is "the progressive loss of material due to the mechanical interaction between a surface and a fluid or solid particles" [ $\left.{ }^{1}\right]$. Erosion resistance of a material depends on many factors, including target material properties and process conditions such as particle velocity, collision angle, temperature and erodent properties. Moreover, the erosion rate should be proportional to the energy exchange between the erodent and the impacted material surface. Different particles transfer the energy to the target over a different volume, thereby causing different energy densities in the target material and different mechanisms and rates of damage.

In impact mechanics, there are different approaches to the interaction of solid bodies. One of the first approaches was developed by Newton in the 17th century. Energy exchange may be described in terms of dynamic coefficients. 
Classical theory of impact, based on the Newton's second law, continues to be successfully used to model the process of two-body collision. The equations involve coefficients of velocity restitution after the collision, impulses and momentum. Further, approaches considering frictional forces were developed. A comprehensive review of the collision models has been presented in $\left[{ }^{1}\right]$. Depending on the contact process and the approach, solution of the model equations can involve mathematical methods ranging from linear algebraic to nonlinear differential equations. The objectives of this paper are the proper use, interpretation and measurement of the dynamic coefficients in the case of solid particle contacts with a flat solid surface.

Since the energy exchange is related to velocity and to the angle of impact, these coefficients are to be determined with a great care. As dynamic coefficients are not material constants, the coefficients must be evaluated experimentally or analytically related to the contact process. Any change in energy loss due to material effects can easily be masked by a small change in velocity. To clarify the details of the two-body interaction, a special test facility, equipped with a digital video camera, was worked out and used.

\section{IMPACT MECHANICS WITH APPLICATION TO ENERGY LOSS}

The problem to be approached is that of a solid particle impacting a massive flat surface. Figure 1 shows a diagram of the particle-wall collision. The axes $t$ and $n$ are chosen tangential and normal to the plane surface of the specimen, respectively.

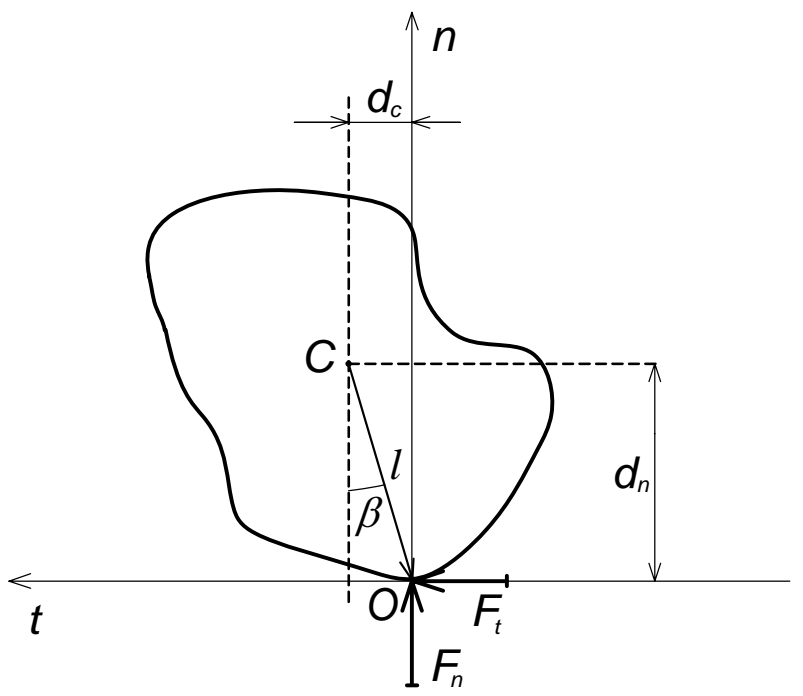

Fig. 1. Diagram of the two-body interaction. 
The appropriate equations are well known $\left[^{2}\right]$ and their mathematical evaluation and interpretation are given in detail elsewhere $\left[{ }^{2-4}\right]$. In our case, the equations can be written as follows $\left[{ }^{2}\right]$ :

$$
\begin{gathered}
v_{n_{2}}+d_{c} \Omega=-k\left(v_{n_{1}}+d_{c} \omega\right), \\
f v_{n_{2}}-v_{t_{2}}=f v_{n_{1}}-v_{t_{1}}, \\
m d_{c} v_{n_{2}}-m d_{n} v_{t_{2}}-I \Omega=m d_{c} v_{n_{1}}-m d_{n} v_{t_{1}}-I \omega,
\end{gathered}
$$

where $v_{n_{1}}$ and $v_{t_{1}}$ are the normal and tangential components of the particle velocity before collision, respectively, $v_{n_{2}}$ and $v_{t_{2}}$ are the normal and tangential components of the particle velocity after collision, describing the movement of the centre of the mass $C, \Omega$ and $\omega$ are the final and initial angular velocities, respectively, and $I$ is the moment of inertia. Equation (1) contains a coefficient $k$ that expresses the process of the normal velocity restitution of particles at the point $O$. It is obvious that the value of $k$ is between 0 and 1 . The coefficient $f$ in Eq. (2) represents the process of tangential velocity restitution and is named the coefficient of dynamic friction. Finally, Eq. (3) expresses the conservation of the angular momentum about the point $O$.

The assumption of sphericity of the solid particle simplifies the equations to a great extent, and in the case of a ball the equations can be rewritten as $\left.{ }^{2}\right]$

$$
\begin{gathered}
v_{n_{2}}=-k v_{n_{1}}, \\
v_{t_{2}}-v_{t_{1}}=-f(1+k) v_{n_{1}}, \\
\Omega-\omega=\frac{f(1+k) v_{n_{1}} \lambda}{R},
\end{gathered}
$$

where $R$ is the particle radius and $\lambda=R^{2} / \varphi^{2}$ ( $\varphi$ is the radius of gyration); for a solid sphere

$$
\lambda=5 / 2
$$

Generally, these equations correspond to the case when a sliding movement of the sphere takes place. When sliding finishes, the particle will either stop or roll.

A discussion of the conditions under which sliding ceases, allowing an adhesion to take place, has been presented in $\left[^{2}\right]$. However, it is worth mentioning that the dynamic friction coefficient is small enough and that prevents occurrence of the adhesion processes between the particle and the target material. According to $\left[{ }^{2,5}\right]$, the boundary condition for sliding is as follows:

$$
f \leq \frac{2}{7} \frac{\left(v_{t_{1}}-R \omega\right)}{(1+k) v_{n_{1}}} .
$$


For non-sliding conditions a general solution corresponds to the rolling of particles and the equations should be replaced by $\left[{ }^{2}\right]$

$$
\begin{gathered}
v_{n_{2}}=-k v_{n_{1}}, \\
v_{t_{2}}-v_{t_{1}}=-\frac{2}{7}\left(v_{t_{1}}+R \omega\right), \\
\Omega-\omega=-\frac{5}{7} \frac{1}{R}\left(v_{t_{1}}-R \omega\right) .
\end{gathered}
$$

The loss of the kinetic energy $K$ is expressed as:

$$
K=\frac{1}{2} m\left(v_{n_{1}}^{2}+v_{t_{1}}^{2}\right)+\frac{1}{2} I \omega^{2}-\frac{1}{2} m\left(v_{n_{2}}^{2}+v_{t_{2}}^{2}\right)-\frac{1}{2} I \Omega^{2} .
$$

Equation (11) can be rewritten in terms of Eqs. (4), (5) and (6):

$$
K=\frac{1}{2} m v_{n_{1}}^{2}(1+k)\left[1-k+2 f b-f^{2}(1+k)(1+\lambda)\right],
$$

where $b=\left(v_{t_{1}}-R \omega\right) / v_{n_{1}}$.

The energy loss can be expressed in a more convenient, non-dimensional form by dividing $K$ by the initial kinetic energy of a particle. This normalized energy $K^{*}$ is expressed as

$$
K^{*}=\frac{1-k^{2}}{1+b^{2}}+\frac{b^{2}}{1+b^{2}} \frac{1}{1+\lambda} \frac{f}{f_{c}}\left(2-\frac{f}{f_{c}}\right),
$$

where $f_{c}$ is the maximal value of the coefficient of dynamic friction:

$$
f_{c}=\frac{1}{1+\lambda} \frac{b}{1+k} .
$$

Equation (14) approaches the expression (7) in the case of a solid sphere.

For some applications, the coefficients may be determined with an analytical procedure like the dynamic finite element analysis, or experimentally. Therefore the main task of this study is experimental determination of the coefficients of restitution to calculate the particle energy loss or the energy, absorbed by the target material during the impact.

\section{EXPERIMENTAL PROCEDURE AND MATERIALS}

A schema of the test equipment used for the measurements of particle velocities and impact angles is shown in Fig. 2. An Ar-Ion laser beam was used 
to illuminate the working area $\left.{ }^{5,6}\right]$. The light area was produced by widening the laser beam with a cylindrical lens. The impact event was recorded with a digital video camera and transferred into a PC. The video images were then decomposed into individual frames with software. A calibration procedure was carried out to eliminate any distortions.

Figure 2 shows the particle accelerator, which was specially developed by SIVUS GmbH at Chemnitz University of Technology, Germany, for the determination of dynamic coefficients. The particles leave the feeding system and enter the particle accelerator (a rotating disk). This accelerator permits a precise evaluation of the collision variables. A centrifugal force drives particles through the channels of the accelerating disk that is set in rotation by a circulating belt $\left[{ }^{5,7}\right]$. Being pushed by the centrifugal force, the particles move towards a target that can be fixed at a corresponding angle onto a bracket of the cover. Therefore the particles outlet has a fixed spatial position and a negligible rotation.

Steel and ceramic-metal composites (cermets) of different composition were used as target materials. Composition of the tested materials and hardness ratio of the material and glass particles $(\mathrm{HV}=540)$ are listed in Table 1 .

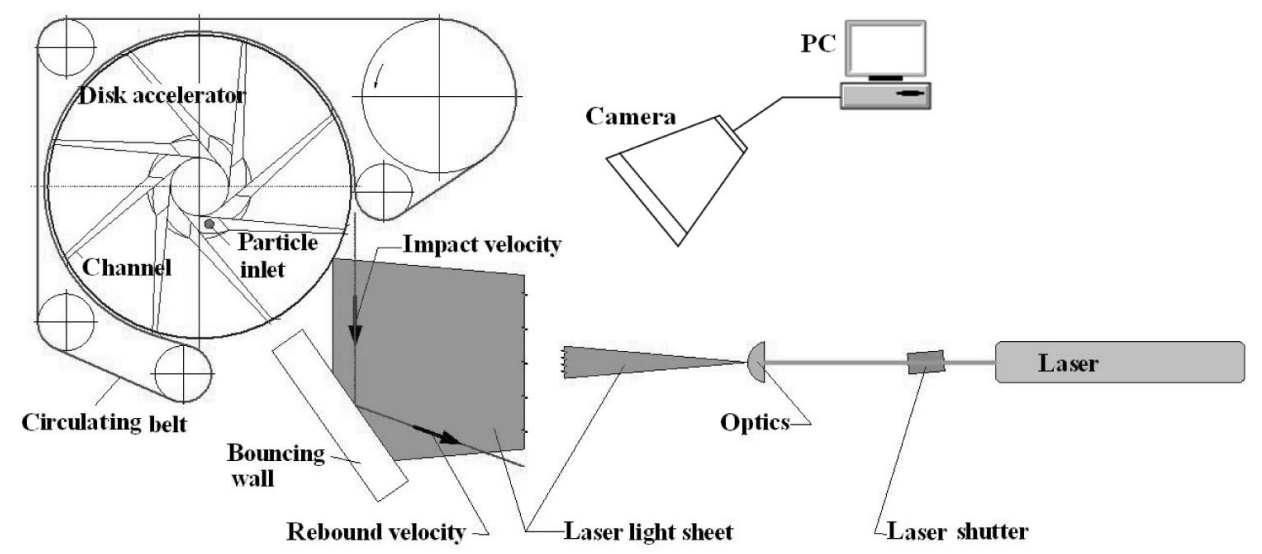

Fig. 2. Experimental facility.

Table 1. Composition and mechanical properties of materials tested

\begin{tabular}{l|l|c|c}
\hline \multicolumn{1}{c|}{ Grade } & \multicolumn{1}{c|}{ Composition } & $\begin{array}{c}\text { Vickers } \\
\text { hardness, } \mathrm{HV} 10\end{array}$ & $\begin{array}{c}\text { Hardness ratio, } \\
\mathrm{HV}_{\mathrm{m}} / \mathrm{HV}_{\mathrm{p}}\end{array}$ \\
\hline $\mathrm{C} 20$ & $80 \mathrm{wt} \% \mathrm{Cr}_{3} \mathrm{C}_{2}+20 \mathrm{wt} \% \mathrm{Ni}$ & 1140 & 2.11 \\
$\mathrm{~W} 15$ & $85 \mathrm{wt} \% \mathrm{WC}+15 \mathrm{wt} \% \mathrm{Co}$ & 1258 & 2.33 \\
$\mathrm{C} 20 \mathrm{~S}$ & $80 \mathrm{wt} \% \mathrm{Cr}_{3} \mathrm{C}_{2}+20 \mathrm{wt} \% \mathrm{Ni}$ (reaction sintering) & 1233 & 2.28 \\
$\mathrm{St}$ & $16 \mathrm{MnCr} 5$ steel & 740 & 1.37
\end{tabular}




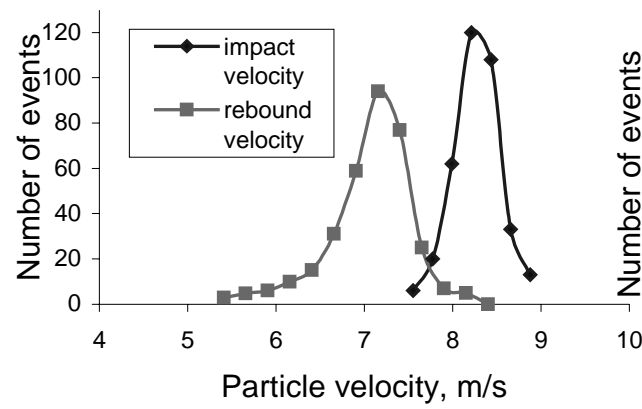

(a)

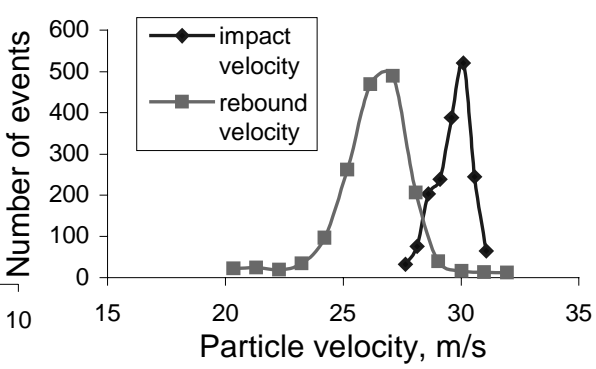

(b)

Fig. 3. Distribution of initial and rebound particle velocities: (a) grade $\mathrm{C} 20$ as the target and impact angle of $75^{\circ}$; (b) grade W15 as the target and impact angle of $30^{\circ}$.

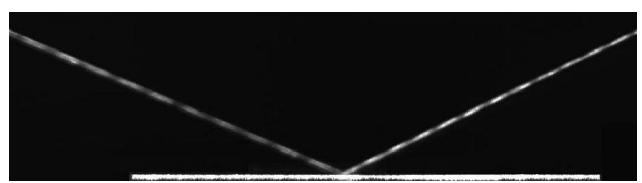

(a)

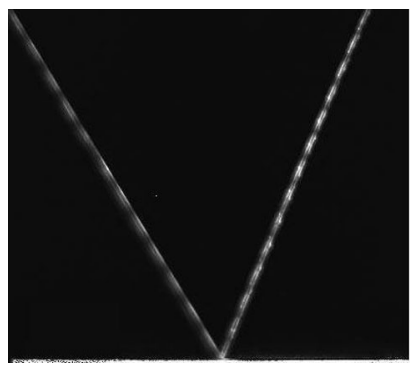

(b)

Fig. 4. Particle tracks obtained with the video camera: (a) impact angle $30^{\circ}$; (b) impact angle $60^{\circ}$.

The particle velocity before impact was 10 and $30 \mathrm{~m} / \mathrm{s}$ and the collision angle was from 15 to $85^{\circ}$. The $125-\mu \mathrm{m}$ glass beads were used as the impacting particles. A characteristic distribution of the bead velocity is illustrated in Fig. 3. Because of some deviation from the initial velocity, mean velocity is shown. A view of particle tracks is shown in Fig. 4.

Results of a study of the steel target - glass ball interaction are described in $\left[{ }^{7,8}\right]$.

\section{RESULTS AND DISCUSSION}

The boundary conditions for the sliding impact can be rewritten using Eq. (7) with $\omega=0$ as follows:

$$
f_{c} \leq \frac{2}{7} \frac{1}{1+k} \frac{1}{\tan \alpha_{1}}
$$


where $\alpha_{1}$ is the impact angle. The coefficients of the velocity restitution $k$ and of the dynamic friction $f$ can be calculated as

$$
\begin{gathered}
k=\frac{\left|v_{n_{2}}\right|}{\left|v_{n_{1}}\right|}, \\
f=\frac{\left|v_{t_{2}}-v_{t_{1}}\right|}{(1+k)\left|v_{n_{1}}\right|} .
\end{gathered}
$$

The experimental data about the variation of the coefficients with the impact velocity and angle are presented in Figs. 5, 6 and 7. For composite materials the coefficient of restitution decreases slightly when the impact angle increases. Much lower rebound effect is observed when a more plastic material (steel) is

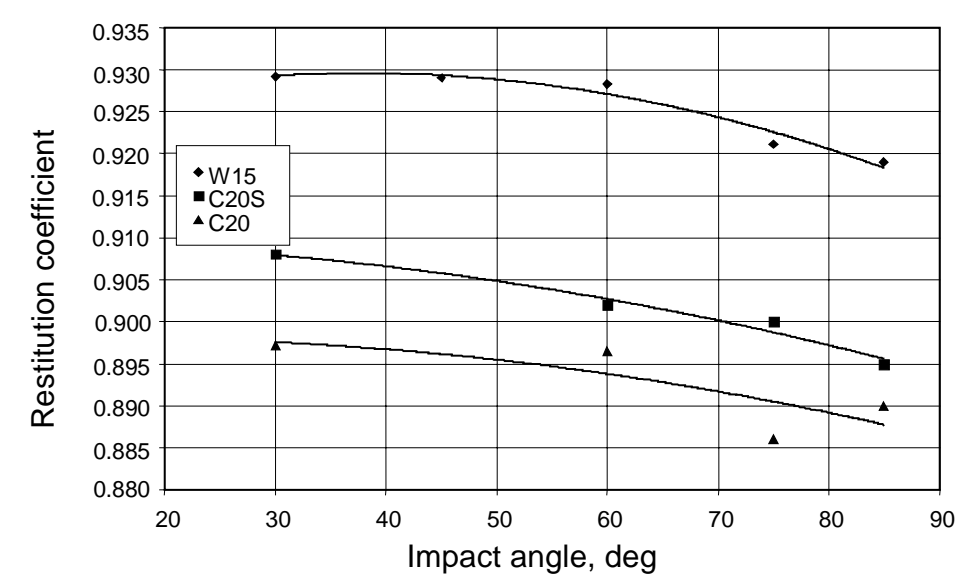

(a)

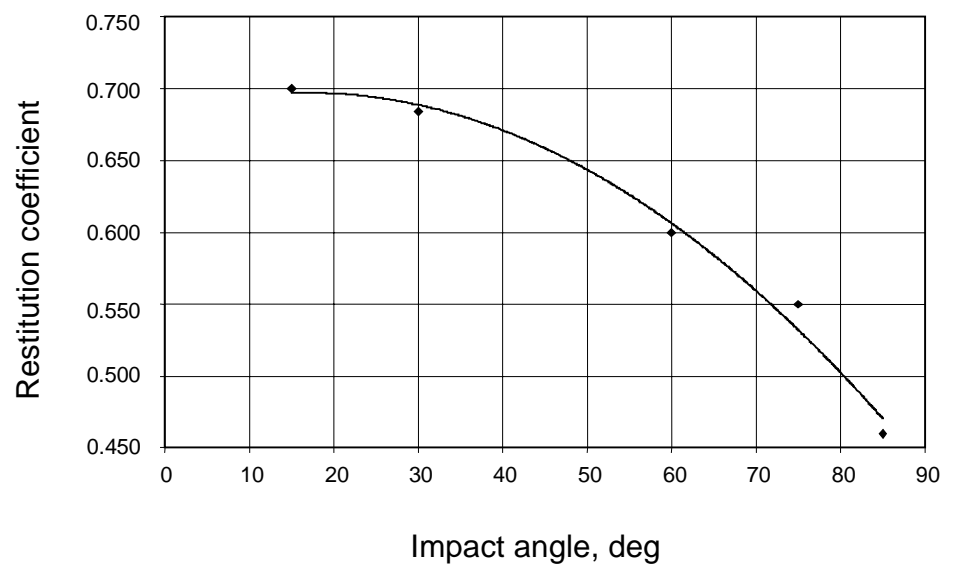

(b)

Fig. 5. Coefficient of velocity restitution vs impact angle: (a) cermets; (b) steel. 
tested (Fig. 5b). An interesting effect can be noticed when the dependence of $k$ on the initial impact velocity of the particle is studied (Fig. 6). It should be mentioned that similar effect of initial increase of $k$ has been observed when composite targets were impacted with glass beads of much larger size of $650 \mu \mathrm{m}$ in diameter (Fig. 6b). Some increase in the coefficient of restitution can be explained by the compression of the target material. Impacting particle squeezes out the plastic binder and plunges hard carbide grains into a soft substratum without any failure. Carbide grains loose their protective binder, forming a thin subsurface transition layer with strength parameters differing from the bulk body

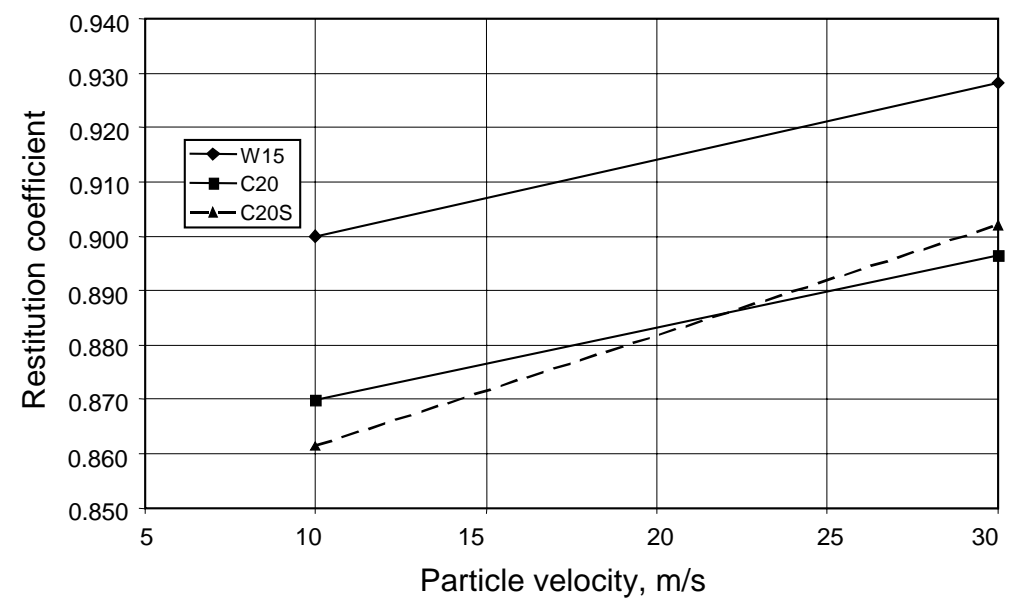

(a)

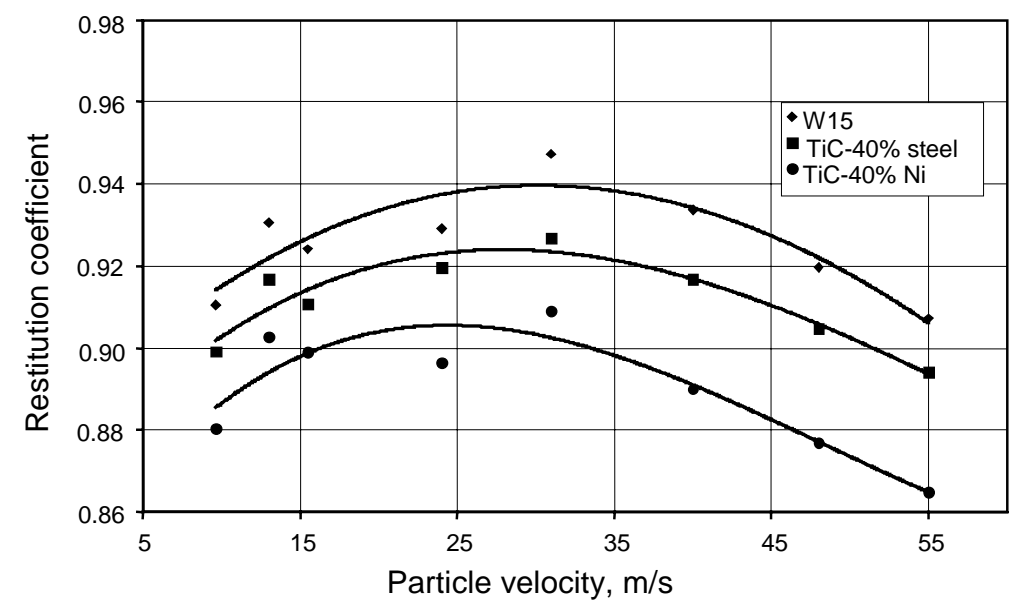

(b)

Fig. 6. Coefficient of velocity restitution vs particle velocity: (a) present study; (b) $\left[^{7}\right]$. 


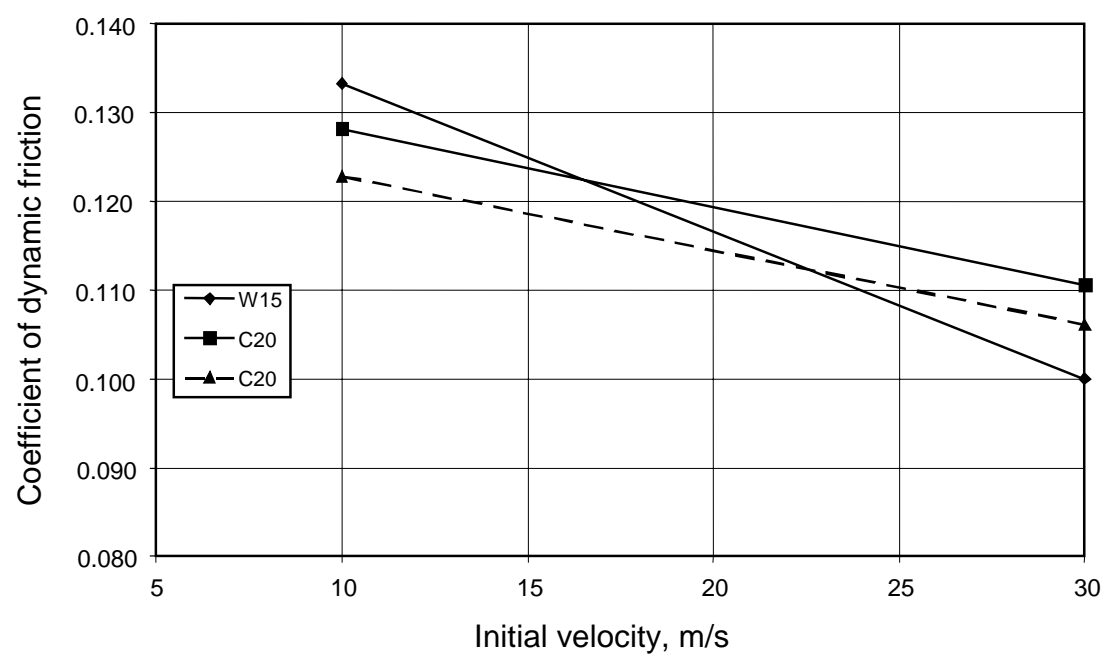

(a)

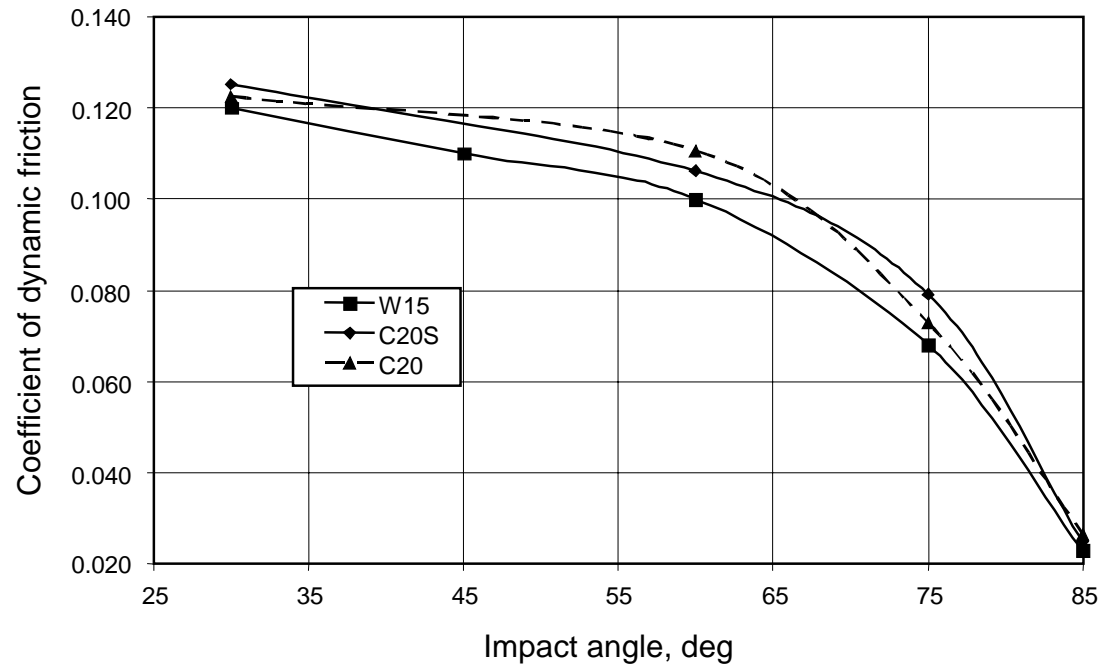

(b)

Fig. 7. Coefficient of dynamic friction: (a) vs particle velocity; (b) vs impact angle.

parameters. In all probability, some energy is accumulated by interphases up to the velocity when tensile stresses both in the target surface and particle initiate crack propagation $\left[{ }^{9}\right]$.

As it was expected, $f$ is a function of both impact angle and initial velocity of the particle (Fig. 7). Moreover, the coefficient of friction depends on the relative sliding velocity between the particle and the target and may be estimated 
through $f_{c}$. In the present case, the sliding velocity decreases with the increase in the impact angle and velocity and the particle can start rolling. In ductile materials high shear strength is accumulated in the sub-surface regions of the target material because of friction-induced plastic deformation. That results in a high friction coefficient $\left[{ }^{10}\right]$. Cermets mostly show brittle fracture with relatively low resistance to crack extension, originating from pre-existing defects. Energy release is more likely achieved through the formation of fracture surfaces rather than through plastic or viscoplastic processes, as compared to the more ductile materials of similar strength.

Taking into consideration Eqs. (15) to (17), the energy loss can be evaluated as

$$
K^{*}=(1-k)^{2} \sin ^{2} \alpha_{1}+\frac{2}{7} \frac{f}{f_{c}}\left(2-\frac{f}{f_{c}}\right) \cos ^{2} \alpha_{1}
$$

With $f / f_{c}$, the first term in Eq. (18) expresses the fraction of the energy loss due to the normal inelasticity alone. The second term corresponds to the fraction of the energy loss due to the tangential effect. Thus Eq. (18) becomes

$$
K^{*}=K_{n}^{*}+K_{t}^{*}
$$

Here $K_{t}^{*}$ depends on $k$ through $f_{c}$. Both terms of the normalized energy loss are plotted in Fig. 8.

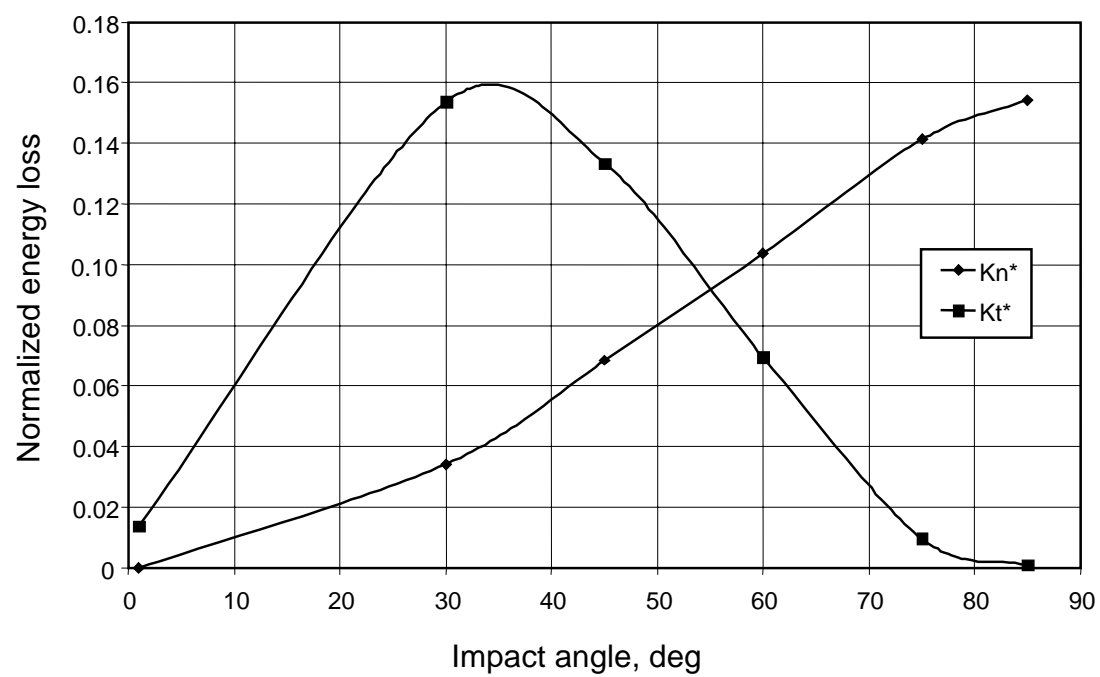

Fig. 8. Effect of the impact angle on the normal and tangential part of the normalized energy loss in the case of W15 cermet. 
This reveals that the energy loss at smaller impact angles is almost exclusively caused by the tangential forces. Both compressive and tangential losses have the same order of magnitude at the impact angle of about $60^{\circ}$. Compressive effects dominate at angles close to $90^{\circ}$.

Energy loss due to inelasticity is insufficient, because material hardness exceeds the particle hardness and relatively soft but brittle particles are not able to cause plastic flow in a hard target. In the case of elastic impact, the energy absorbed at oblique impact includes a substantial component attributed to the energy dissipation by frictional effects at the particle-target interface and the component of the energy, transmitted to the surface, depends strongly on the impact angle through the coefficient of dynamic friction. A large portion of the incident energy is dissipated via elastic-plastic deformation and heating in the near-surface regions $\left[{ }^{11}\right]$. Figure 9 shows the normalized energy, absorbed by two cermets.

The initial stage of material damage can be studied by means of a scanning electron microscope. Single impact craters produced by a glass sphere into the surface of W15 and C20 cermets are presented in Fig. 10. The isolated impact sites reveal different mechanisms of material failure for different composites. As compared with the relatively ductile WC-Co, impact site of the $\mathrm{Cr}_{3} \mathrm{C}_{2}$-based cermet shows much more brittle response.

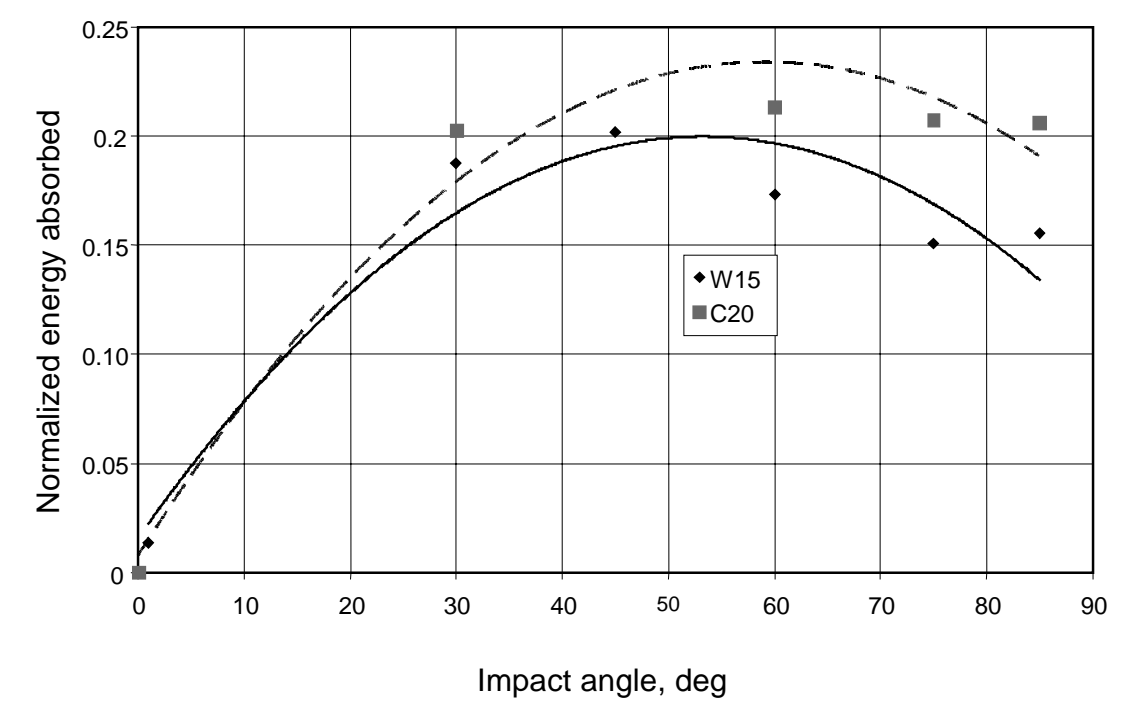

Fig. 9. Effect of the impact angle on the normalized energy, absorbed by cermets. 


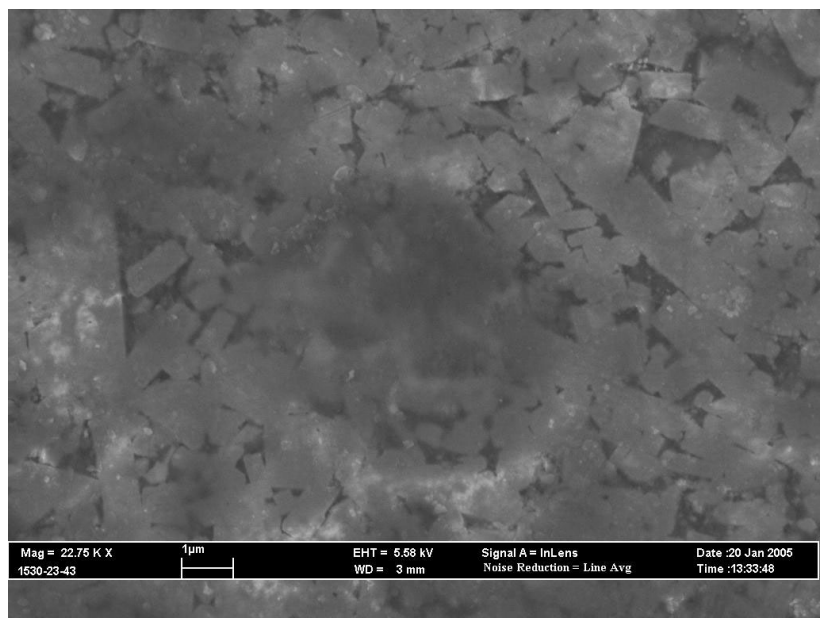

(a)

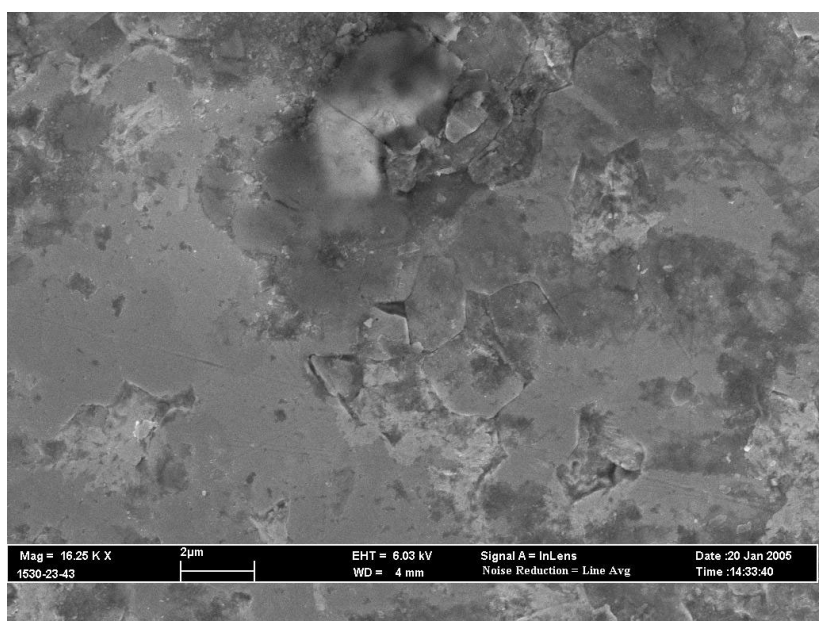

(b)

Fig. 10. Single impact craters after collision at the impact angle of $75^{\circ}$ : (a) W15; (b) C20.

\section{CONCLUSIONS}

The magnitude of the energy, absorbed during each impact, is a function of the impact angle and frictional effects. It plays the most important role in the energy release under conditions of two-body interaction. To apply the energy loss expression and to study the impact wear dependence on the energy absorbed by a surface, two coefficients are to be estimated. These are the classical coefficient of 
velocity restitution, $k$, and the dynamic friction coefficient, $f$. The method and test equipment proposed above permit the estimation of the coefficients experimentally. Energy, absorbed by the target material, gives information about the two-body interaction process. Moreover, tests allow simulation of single or multi-impacts of controlled energy. The initial stages of the erosion damage can be examined.

\section{ACKNOWLEDGEMENTS}

The authors would like to express their gratitude to MSc. O. Volobujeva for her assistance by obtaining the SEM micrographs, Dr. J. Pirso for supplying the test specimens and the DAAD Foundation, Germany, for funding a fellowship for this study. This research was also supported by the Estonian Science Foundation (grants Nos. 6163 and 6660).

\section{REFERENCES}

1. Mac Sithigh, G. P. Rigid body impact with friction - various approaches compared. In Impact Mechanics: Experiment, Theory and Calculation. ASME-AMD, NY, 1995.

2. Brach, R. M. Impact dynamics with application to solid particle erosion. Int. J. Impact Eng., 1988, 7, 37-53.

3. Brach, R. M. Formulation of rigid body impact problems using generalized coefficients. Int. J. Eng. Sci., 1998, 36, 61-71.

4. Stronge, W. J. Swerve during three-dimensional impact of rough bodies. J. Appl. Mech., 1994, 61, 605-611.

5. Schade, K.-P. and Hädrich, T. Investigation of influence of wall roughness on particle-wall collision. In Proc. Third International Conference on Multiphase Flow ICMF'98. Lyon, 1998, 1-8.

6. Petrak, D. Development in fiber-optical spatial filter velocimetry. In Proc. 2-nd International Conference on Multiphase Flow. Kyoto, 1995, Vol. 1, 9-13.

7. Schade, K.-P., Erdmann, H.-J. and Petrak, D. Experimental investigations of the particle-wall collision under particular consideration of the wall roughness. Fluids Eng. Div., ASME, NY, 1996, 236, 759-766.

8. Hussainova, I., Kubarsepp, J. and Shcheglov, I. Investigation of impact of solid particles against hardmetal and cermet targets. Tribol. Int., 1999, 32, 337-344.

9. Hussainova, I., Kubarsepp, J. and Pirso, J. Mechanical properties and features of erosion of cermets. Wear, 2001, 250, 818-825.

10. Sundararajan, G. The energy absorbed during the oblique impact of a hard ball against ductile target materials. Int. J. Impact Eng., 1990, 9, 343-358.

11. Hussainova, I. Microstructure and erosive wear in ceramic-based composites. Wear, 2005, 258, $357-365$. 


\title{
Dünaamilised koefitsiendid löögimehaanikas
}

\author{
Irina Hussainova, Klaus-Peter Schade ja Sergei Tisler
}

Erosiooni kiirus sõltub energia vahetusest osakese ja katsetatava materjali vahel. On toodud kahe tahke keha kokkupõrke valemi analüüs neelduva energia arvutamiseks sfäärilise osakese löögil vastu tasapinnalist katsetatavat materjali. On näidatud, et energia neeldumine on ranges sõltuvuses dünaamilistest koefitsientidest, mida töös on nimetatud kiiruse restauratsiooni koefitsiendiks pärast lööki $(k)$ ja dünaamiliseks hõõrdekoefitsiendiks $(f)$. On kirjeldatud uut meetodit ja eksperimentaalseadet nende koefitsientide määramiseks. 